\title{
$O$ uso de ferramentas no processo de formação de gerentes de Unidades Básicas de Saúde: um relato de experiência
}

\author{
The use of tools in the training process of Basic Health Units \\ managers: an experience report \\ Karina Cenci Pertile', Ana Paula Azevedo Hemmi', Camila Zamban de Miranda', Frantchesca \\ Fripp dos Santos ${ }^{2}$
}

DOI: $10.1590 / 0103-110420195611$

\begin{abstract}
RESUMO O objetivo deste trabalho foi relatar e refletir sobre a experiência vivida no processo de ensino da gerência em Unidades Básicas de Saúde, com foco na oferta de ferramentas para o desenvolvimento do trabalho gerencial, a partir do Curso de Aperfeiçoamento em Gerência de Unidades Básicas de Saúde, Gestão da Clínica e do Cuidado, ofertado pela Universidade Federal Fluminense em parceria com o Ministério da Saúde, nos anos de 2016 a 2019. Foi realizada uma breve descrição do curso com destaques aos encontros virtuais e presenciais, enfatizando as estratégias utilizadas para aprimorar a prática dos gerentes. O processo de ensino-aprendizagem se desenvolveu pautado na dialogicidade e na problematização, envolvendo não só os profissionais-alunos, mas também se estendendo aos espaços de trabalho deles. Foram ofertadas ferramentas para a qualificação do trabalho gerencial nas Unidades Básicas de Saúde, que parecem ter produzido reflexões sobre o cuidado prestado. Além disso, o curso oportunizou um processo de construção de grupalidade entre os profissionais-alunos, por meio das dinâmicas adotadas tanto para os encontros virtuais quanto para os presenciais.
\end{abstract}

PALAVRAS-CHAVE Atenção Primária à Saúde. Capacitação profissional. Gestão em saúde.

ABSTRACT This paper's objective is to report and reflect about the experience of management training process in Basic Health Units, focusing on the supply of tools for the development of managerial work, starting from the Course of Improvement in Management of Basic Health Units, Clinic and Care Management, offered by the Fluminense Federal University (UFF) in partnership with the Ministry of Health from 2016 to 2019. A brief description of the course was done highlighting the virtual and presential meetings, especially the strategies used. The teaching-learning process was developed based on dialogicity and problematization, involving not only the professionals-students, but also extending to their workspaces as well. Tools were offered to qualify the management work at the Basic Health Units, which seem to have produced reflections on the promoted care. Furthermore, the course gave opportunity to the construction process of groupality among the professionals-students, through dynamics adopted during the virtual meetings as well as during the presential ones.

1 Universidade Federal dos Vales do Jequitinhonha e Mucuri (UFVJM) -

Diamantina (MG), Brasil. kapertile@gmail.com

2 Secretaria Municipal de Saúde - Serro (MG), Brasil.
KEYWORDS Primary Health Care. Professional training. Health management. 


\section{Introdução}

A discussão em torno do papel do gerente de Unidades Básicas de Saúde (UBS) remonta à década de $1990^{\mathbf{1}, 2}$, quando já havia o debate sobre a importância desses atores na implementação da Reforma Sanitária brasileira, com a compreensão de que a forma como os estabelecimentos de saúde são gerenciados implica a produção de modelos de atenção à saúde na perspectiva da micropolítica do processo de trabalho². Em 2012, com a publicação da Política Nacional de Atenção Básica (PNAB), a prática gerencial já havia sido apontada como algo importante para o desenvolvimento de ações sanitárias democráticas e participativas ${ }^{3}$, porém, é por meio da Portaria $n^{\circ} 2.436$, de 21 de setembro de 2017, a qual estabelece uma revisão de diretrizes para a organização da Atenção Básica (AB), no âmbito Sistema Único de Saúde (SUS), que o Ministério da Saúde (MS) afirma e recomenda explicitamente a necessidade de um gerente local ${ }^{4}$. No entanto, apesar da recomendação e do reconhecimento da importância de gerentes, percebe-se que nem todos os municípios brasileiros contam com esses profissionais em suas UBS. Além disso, em grande parte dos municípios onde há gerentes nas UBS, eles não têm formação específica para atuar no cargo ${ }^{5,6}$.

Em relação a esse último aspecto, um estudo recente 7 mapeou os cursos de gestão em saúde, considerando os diferentes níveis de formação para a qualificação de gestores. $\mathrm{O}$ estudo evidenciou que há um direcionamento desses cursos para a área hospitalar, tanto na graduação quanto na pós-graduação e na especialização. Outro aspecto se refere à oferta desses cursos, que ocorre majoritariamente por meio de instituições privadas?.

Desde 2016, no sentido de diminuir as lacunas relacionadas com a formação para a gerência dos serviços de Atenção Básica à Saúde e considerando a complexidade que a função de gerente exige, o MS passou a ofertar, em parceria com a Universidade Federal Fluminense (UFF), o Curso de Aperfeiçoamento em
Gerência de Unidades Básicas de Saúde, Gestão da Clínica e do Cuidado. Este curso, atualmente, encontra-se em sua terceira edição e acontece em inúmeras regiões do Brasil na modalidade semipresencial. O público-alvo são profissionais de saúde com nível superior que possuem atuação na $\mathrm{AB}$ exercendo função gerencial, por isso, não são alunos somente, mas profissionais-alunos. $\mathrm{O}$ curso tem como um dos seus objetivos instrumentalizar esses profissionais para que possam aprimorar o processo de trabalho das equipes, apoiando a incorporação de ferramentas de gestão da clínica e do cuidado na AB.

Para que esse curso pudesse ser ofertado em diversas regiões do País, foi necessário contar com a presença de tutores, que foram selecionados por meio de um processo seletivo e que, além de experiência em Ensino a Distância (EaD), deveriam, necessariamente, ter atuado em atividades gerenciais no âmbito da $\mathrm{AB}$ por, pelo menos, cinco anos, além de possuir pós-graduação em áreas relacionadas com a gestão de políticas públicas ou em saúde coletiva. Os tutores, após seleção, passaram por um processo formativo que aconteceu de forma presencial no município de Niterói/Rio de Janeiro, por meio do qual foi possível discutir a proposta do curso com a equipe pedagógica, aprender sobre o uso de ferramentas que seriam trabalhadas com os profissionais-alunos e construir vínculos, que também se tornaram uma ferramenta de trabalho muito importante. Nesse momento, formaram-se grupos de tutores por região do Brasil, sendo que cada região conta com um coordenador pedagógico da UFF, o qual atua como referência dos tutores.

Na região Sudeste, formaram-se turmas nos estados de Espírito Santo, Minas Gerais, Rio de Janeiro e São Paulo. No caso de Minas Gerais, o total de alunos selecionados a cada ano tem sido distribuído entre dois ou três tutores, e este relato e reflexão advém do contato com turmas dos anos de 2016, 2017 e 2018 por uma das tutoras desse estado. A cada ano, o grupo foi formado por profissionais-alunos com 
perfis diferentes entre si. Enquanto a turma que iniciou o curso em 2016 foi formada basicamente por profissionais de Belo Horizonte, Minas Gerais, e sua Região Metropolitana, a de 2017 teve a sede dos encontros presenciais em Belo Horizonte, porém foi formada predominantemente por profissionais-alunos de municípios do interior do estado. Por sua vez, a turma que iniciou o curso em 2018 foi uma aposta da coordenação nacional em levar a formação para regiões do interior do estado que apresentam poucas ofertas de qualificação profissional, como no caso dos Vales do Jequitinhonha e do Mucuri por exemplo.

O contato com inúmeros alunos com perfis, procedências e, sobretudo, experiências distintas nos permitiu realizar algumas reflexões sobre o ensinar a ser gerente. Além disso, o acompanhamento das transformações que foram acontecendo nos espaços de trabalho, a partir das ferramentas e reflexões oportunizadas, também subsidiaram as reflexões aqui colocadas. Dessa forma, o objetivo deste trabalho é relatar e refletir sobre a experiência vivida no processo de ensino da gerência em UBS no estado de Minas Gerais com foco na oferta de ferramentas para o desenvolvimento do trabalho gerencial.

\section{O curso de formação para gerentes de Unidades Básicas de Saúde}

A proposta do Curso de Aperfeiçoamento em Gerência de Unidades Básicas de Saúde, Gestão da Clínica e do Cuidado está organizada em três Unidades de Aprendizagem (UA1, 2 e 3) que estão previstas para ocorrer em um período de 24 semanas, com uma carga horária total de 180 horas, distribuídas em 132 horas a distância e em 48 horas de forma presencial. As horas realizadas a distância acontecem via Ambiente Virtual de Aprendizagem (AVA), a partir de um software desenvolvido pela UFF. As horas presenciais acontecem em três momentos distintos, sendo um antes do início do curso, outro ao final da UAl e o último no encerramento. Essas Unidades foram organizadas em três macrocompetências, elencadas como essenciais a um gerente de UBS: gestão do trabalho; gestão de insumos; e gestão de redes. Na discussão de cada macrocompetência, são ofertadas ferramentas que visam à qualificação do trabalho dos gerentes.

O termo ferramenta está sendo utilizado, aqui, como um instrumento que permite que do abstrato seja possível chegar à objetivação, ou seja, permite àquele que dela se utiliza produzir concretude e materialidade em determinadas situações, com a intencionalidade de projetar e operar mudanças e transformações ${ }^{8}$. Assim, pode-se dizer que os saberes de cada profissional fazem parte da sua caixa de ferramentas que, quando utilizadas, geram maiores possibilidades de compreender os problemas e maior capacidade de enfrentá-los de modo adequado?

A UAl, por meio da qual se discute a gestão do trabalho, acontece por um período de 11 semanas, e aborda os seguintes temas: processo de trabalho em saúde e produção do cuidado; gestão compartilhada; gerência e coordenação de grupos; gerenciamento de conflitos.

A gestão de insumos é trabalhada na UA2, com uma duração de três semanas, abordando questões relacionadas com a gestão de materiais; gerenciamento de estoque de materiais de consumo e ambiência nas UBS.

A gestão de redes é abordada na UA3, possui uma duração de dez semanas e aborda as redes de atenção à saúde como possibilidade para o cuidado, projeto terapêutico singular, regulação e planejamento em saúde.

Cada uma dessas UA é composta por um conjunto de aulas, organizadas por intermédio de um e-book, disponibilizado no AVA, desde o início do curso. Assim, os profissionais-alunos possuem acesso a todas as aulas e podem utilizá-las para além dos momentos em que estiverem sendo discutidas no AVA, à medida que sentirem interesse ou necessidade, ou ainda perceberem que elas podem auxiliar em processos que estão vivendo no trabalho. Em 
cada unidade, existem atividades avaliativas que propõem que as ferramentas discutidas na UA sejam utilizadas nos espaços de trabalho e que se produza uma reflexão a partir dessa experiência, que deve ser sistematizada em uma narrativa. Considerando a problematização como base pedagógica do curso, que se pauta no questionamento, reflexão e intervenção na própria realidade ${ }^{10}$, os alunos são convidados a refletir sobre o seu processo de trabalho e, ao mesmo tempo, a construir elementos de melhoria para a qualidade da assistência e do cuidado. Assim, trabalha-se também na perspectiva do desenvolvimento de competências, entendidas como

[...] a capacidade de os indivíduos mobilizarem suas potencialidades de forma integral, pertinente ao seu campo profissional, em contextos diversos, para resolverem um determinado probleman1(125).

Esse processo acontece mediado pelo tutor, com o grupo de profissionais-alunos e com as suas respectivas equipes de trabalho. Os encontros produzidos, tanto em ambiente virtual quanto presencial, dão singularidade ao curso; portanto, daremos destaque ao uso das ferramentas e às experiências vivenciadas neles.

\section{Os encontros virtuais}

As UA possuem suas particularidades devido aos diferentes temas abordados, porém a dinâmica de trabalho é semelhante, já que, em todas, os profissionais-alunos são orientados a ler as aulas que são apresentadas em formato de textos didáticos sobre os temas disponíveis no AVA, e que servem como ferramentas disparadoras para reflexão, ou mesmo para que sejam utilizadas em discussões no ambiente de trabalho. A proposta é de que as reflexões produzidas a partir das experiências individuais e do material teórico sejam compartilhadas entre o grupo de profissionais-alunos, levadas aos espaços de trabalho e retornem à plataforma, para serem ressignificadas, em um processo de aprendizagem cooperativa ${ }^{\mathbf{2}}$, que exige a capacidade de pensar, de participar e de conviver coletivamente, assumindo corresponsabilização com o grupo, pelo processo de construção de conhecimento.

Considerando que a maior parte da carga horária do curso acontece pelo AVA, são produzidos diversos encontros virtuais por meio de fóruns semanais, os quais são organizados pelo tutor conforme o ritmo e as características de cada grupo. É importante destacar que, apesar de intitularmos esse item como 'encontros virtuais', estes aconteceram de forma assíncrona, ou seja, tratam-se de encontros dos envolvidos com os registros de cada um, seja pelo sentido dado à experiência do outro, seja pelas mediações do tutor, que aproxima as escritas e ajuda na construção compartilhada de conhecimento. Este é o primeiro desafio do tutor: produzir uma mediação em ambiente assíncrono que permita que a troca de experiência, de afecções, de reflexões, seja produtora de um sentido de grupalidade e de construção compartilhada de conhecimento. $\mathrm{O}$ aprendizado por meio de ambientes virtuais é algo desafiador, pois exige que os participantes se sintam à vontade no grupo, porém isso não ocorre naturalmente. Nesse ponto, a elaboração de estratégias que facilitem aproximações e propiciem a aglutinação de novas configurações na rede pode contribuir para a formação de vínculos, tornando possível um compartilhamento de mensagens que amplia as perspectivas de democratização do saber ${ }^{13}$.

Para o desenvolvimento da grupalidade, por meio dos encontros em AVA, foi fundamental a autonomia do tutor para conduzir o processo, especialmente por considerar as especificidades de cada grupo. Em locais, como cidades do Vale do Jequitinhonha e do Mucuri, por exemplo, não existe uma formalização do cargo de gerente de UBS, sendo que os profissionais que exercem as funções gerenciais também são responsáveis por funções assistenciais. Essa realidade é encontrada também em outras regiões do País, especialmente em municípios de pequeno porte, onde a gerência tem sido 
assumida por profissionais já alocados nas UBS, agregando às funções gerenciais aquelas clínico-assistenciais, sendo que a multiplicidade de tarefas tende a comprometer a efetividade do trabalho de gestão $0^{5,14}$. Assim, parece que há uma dificuldade desses profissionais-alunos se reconhecerem como gerentes e de se perceberem como pares; e, para esses, a interação em AVA demorou um pouco para fluir. Nesse caso, para além das reflexões teóricas que foram produzidas, a mediação teve como um dos focos a construção da identidade do grupo. Esse fato chamou atenção pois, com outros profissionais-alunos de municípios como Belo Horizonte e região metropolitana, onde o cargo de gerente já existe há mais de dez anos e com uma definição mais clara de papéis, a interação entre eles, desde o primeiro fórum, ocorreu focada no processo de trabalho da gerência.

As aulas do e-book, disponível no AVA, ofertam inúmeras perguntas problematizadoras, que convidam os profissionais-alunos a discutirem em seus espaços de trabalho, sendo que as experiências vividas a partir dessa discussão também foram temas nos fóruns. São exemplos de questões ofertadas nas aulas do e-book:

[...] pense no papel que você costuma desempenhar em situações de conflito na UBS: você exercita os componentes da Comunicação Não Violenta (CNV) no seu cotidiano? Que tal apresentar os princípios da CNV a sua equipe e depois compartilhar suas impressões com seus colegas de turma no Fórum da UA 1?15(48).

Diante disso, é possível perceber que cabe ao tutor tanto mediar a discussão internamente no fórum quanto incentivar que as reflexões cheguem às equipes de trabalho dos profissionais-alunos. Todavia, é importante propiciar uma constante reflexão, a partir das vivências com as respectivas equipes de trabalho, de forma que retornem aos fóruns e sejam, assim, compartilhadas com os colegas do curso, que passam a ressignificar coletivamente a experiência vivida. Trata-se de um movimento que permite pensar o trabalho como espaço de formação, já que impulsiona os profissionais a pensar e a agir no mundo ${ }^{16}$. Dessa maneira, é possível se construir uma prática pedagógica que auxilie aos profissionais-alunos a buscarem novos significados a partir do que acontece no seu cotidiano de trabalho, mas também discutindo novas perspectivas de abordagem aos problemas que são identificados, a partir das ferramentas apresentadas.

O compartilhar de experiências no fórum extrapolou os limites das ofertas conceituais e representou um dispositivo para o fortalecimento da grupalidade. Como exemplo, têm-se as dificuldades encontradas por diversos profissionais, principalmente das cidades do interior do estado, quando da mudança da gestão municipal. Como o curso, geralmente, inicia-se nos meses de outubro ou novembro de cada ano, as posses de prefeitos, no início de 2017, aconteceram quando o curso estava em pleno desenvolvimento. Essa transição de governos produziu impacto no ambiente de trabalho de alguns dos profissionais-alunos, inclusive porque muitos deles foram demitidos; e, durante esse período, foi possível perceber uma tensão em suas falas durante os fóruns, que refletiam o momento de instabilidade em que viviam.

Apesar de, nesse momento, esperar-se uma diminuição das discussões, os fóruns tiveram um papel fundamental, pois se tornaram uma possibilidade protegida de lugar de encontro para compartilhamento de sentimentos, como medo ou sensação de perseguição, e de construção de soluções. Assim, o que se viu foi o fortalecimento do vínculo e apoio entre os colegas, inclusive alguns incentivando os outros a permanecerem no curso e indicando oportunidades de trabalho. Produziu-se, assim, uma rede de agenciamentos de trabalho.

Por conseguinte, os encontros que se produziram em ambiente virtual tiveram uma dimensão de produção e compartilhamento de conhecimentos e de construção de vínculo, que se fortaleceram a partir dos encontros presenciais, conforme relatado a seguir. 


\section{Os encontros presenciais}

Houve três encontros presenciais para cada uma das três turmas. Esses propiciaram de maneira substancial algumas reflexões no processo de ensino aprendizagem aqui apontado. Tais encontros permitiram um contato próximo com os profissionais-alunos, uma vez que esses ocorrem, geralmente, em dois dias consecutivos com carga horária de 8 horas em cada dia. No desenvolvimento dos encontros presenciais, foram utilizadas estratégias, como dinâmicas de grupo, que permitiram a reflexão e aprendizado sobre o ser gerente e, ao mesmo tempo, deram fluidez a esse momento. Tais estratégias foram pensadas na perspectiva de propiciar um processo de construção de aprendizagem coletivo, com estímulo à capacidade criadora e ao trabalho em equipe, entendendo que esses elementos são importantes no desenvolvimento psíquico e intelectual dos envolvidos ${ }^{17}$. Assim, daremos ênfase às atividades desenvolvidas que demonstraram impacto na transformação de práticas e possibilitaram que esses encontros ocorressem de forma mais leve.

Para a organização dos encontros, são oferecidas diretrizes gerais pela coordenação do curso, no caso, pelos docentes da UFF, os quais indicam os assuntos que devem ser abordados em cada um deles. Entretanto, é delegado aos tutores construir um espaço de ensino-aprendizagem que dê leveza ao trabalho que será desenvolvido, utilizando ferramentas do seu próprio arcabouço, que dialoguem com a proposta do curso e ajudem a produzir sentido no aprendizado a partir da experiência e das sensações produzidas em cada UA. Essa forma de conduzir o processo, além de criar uma corresponsabilização pelo andamento do curso, oportuniza a construção subjetiva em cada um dos encontros. Assim, com a autonomia dos tutores tanto para conduzir as discussões nos encontros virtuais como para a organização dos encontros presenciais, o curso se torna mais personalizado e, de certa forma, mais ajustado às diferentes realidades.
O primeiro encontro presencial acontece, geralmente, antes do início do curso e no local de melhor acesso ao grupo. Nesse momento, o curso, sua plataforma, a dinâmicas das atividades com suas ferramentas e o sistema de avaliação são apresentados aos profissionais-alunos. É também nesse encontro que o grupo se conhece e conversa sobre as suas expectativas. O momento de apresentação pode ser considerado como crucial para criação de vínculo entre tutora e profissionais-alunos e deles próprios entre si. Além disso, esse momento tem demonstrado ser um estímulo a todos para se envolverem e se comprometerem com as atividades ao longo do curso.

Em cada uma das turmas, foram utilizadas estratégias diferentes de apresentação. Assim, se, em um primeiro momento, a preocupação era com a apresentação dos nomes dos participantes, sua procedência e expectativa em relação ao curso, posteriormente, percebeu-se a necessidade em trazer para esse momento uma reflexão sobre o impacto das diferenças culturais na construção do trabalho em equipe. Ter sensibilidade para perceber as diferenças de cada turma foi algo importante para a reflexão sobre como lidar e aprender com as diferenças de cada pessoa, entendendo que os grupos e os espaços de trabalhos não são homogêneos. Pelo contrário, são formados por indivíduos com diferenças sociais e culturais que, por sua vez, interferem nas suas escolhas, nos seus processos de tomada de decisões e na maneira como se relacionam com outras pessoas.

Pensando nisso, para a turma que ingressou em 2018, a apresentação foi realizada por meio de uma dinâmica, em que se utilizou um rolo de barbante. Para a sua realização, o grupo se organizou em círculo, e a primeira pessoa a se apresentar deveria segurar o rolo de barbante, dizer o seu nome e suas expectativas em relação ao curso e, então, segurar a ponta do rolo de barbante e lançá-lo para algum outro participante. Ao receber o rolo de barbante, essa pessoa deveria repetir o que fez o primeiro participante e assim sucessivamente. Após todas as apresentações e como todos 
estavam segurando uma das pontas do barbante nas mãos, foi possível visualizar uma rede. Em seguida, essa rede foi colocada no chão e se transformou em um mapa abstrato, no qual as pessoas tinham que apontar as regiões do País ou do estado de forma a alocar com papeis coloridos os locais por onde cada um já havia morado. Para isso, todos deviam conversar entre si de forma a se ter uma coerência de localizações no mapa. Essa dinâmica permitiu o início do diálogo sobre trabalho em grupo, em que as pessoas presentes pudessem se sensibilizar com a diversidade social e cultural de cada integrante. Foi possível pensar também como as relações acontecem nos espaços de trabalho, já que esses podem ser compostos por pessoas com diferentes histórias, percursos, compreensões sobre os mesmos assuntos, que também geram posturas e posicionamentos diversos.

A partir dessa dinâmica inicial, as expectativas apresentadas pelos profissionais-alunos era de que, com o curso, poderiam aprender a lidar com os problemas existentes nos respectivos ambientes de trabalho que, para alguns, estavam relacionados com as diferenças existentes entre os membros da equipe. Dessa forma, foi necessário pensar em estratégias que pudessem fazer com que os alunos percebessem as diferenças entre eles e que, ao mesmo tempo, oportunizasse a discussão sobre conflitos, começando a percebê-los como oportunidades de aprendizagem e entendendo que estes, quando adequadamente gerenciados, podem representar oportunidades de diálogo, restauração de relações e colaboração ${ }^{15}$. Esse tema perpassou grande parte dos encontros presenciais e esteve presente em todos os grupos. Assim, foi importante trabalhar utilizando-se atividades manuais e danças de roda que pudessem simular situações caóticas ou inesperadas. A partir dessas, iniciaram-se conversas sobre as sensações causadas pelo inusitado, imprevisível, de forma a enxergá-las como possibilidade de se produzir o novo ou o diferente. Uma dessas atividades foi a construção de um origami.

Essa atividade consistiu em realizar dobras a partir de um pedaço de papel quadrado de diferentes cores. Cada pedaço de papel foi entregue a cada profissional-aluno; e, em seguida, foram orientados sobre as dobraduras necessárias para chegar ao resultado esperado. Desse modo, eles deveriam dobrar o papel em linha reta, alinhar as suas pontas e, por fim, desfazer as arestas do papel. Essa atividade, aparentemente simples, exigiu dos participantes um esforço muito intenso, pois foram desafiados em suas habilidades e precisaram se dedicar a resolver uma situação inesperada. Nesse momento, foi possível perceber tensão, irritação e ansiedade. Alguns participantes tiveram muita dificuldade, outros menos, de forma que uns auxiliaram os outros; e, ao final, surgiu uma peça que parecia não fazer nenhum sentido para eles. Então, chegou-se à proposta de encaixar as peças de todo o grupo, algo que exigiu de todos muita atenção, cuidado e paciência. Ao final, o grupo produziu um origami inesperado e bonito, admirado por todos os presentes.

A partir dessa atividade, houve a reflexão sobre a importância do trabalho em equipe, sobre o temor que, às vezes, sentimos pelo imprevisível, pelo diferente; e como isso pode representar uma abertura para as transformações, especialmente se houver pares que estejam dispostos a incentivar uns aos outros nos momentos difíceis. Diante disso, podemos afirmar como as dinâmicas de grupo - por serem pautadas em atividades que permitem aos participantes fazer analogias, associações e transferências oportunizam simultaneamente reflexões que se extrapolam à prática profissional ${ }^{17}$.

Em relação à utilização das ferramentas para o trabalho dos gerentes, um destaque, quando da realização do primeiro encontro presencial, foi o trabalho com as ferramentas disponibilizadas na UAl, que discutem gestão do trabalho, tais como o Fluxograma Descritor do Processo de Trabalho e os Processos Circulares.

O Fluxograma Descritor do Processo de Trabalho é uma representação gráfica de todas 
as etapas das atividades desenvolvidas na UBS, a partir do percurso terapêutico feito pelo usuário ${ }^{\mathbf{1 8}}$, permitindo que as equipes identifiquem problemas e produzam questionamentos sobre seu processo de trabalho, de forma a analisá-lo. Os Processos Circulares, por sua vez, representam uma ferramenta para a construção do diálogo e podem apoiar o gerente no gerenciamento de situações conflituosas envolvendo grupos ${ }^{15}$.

Em relação à abordagem ao Fluxograma Descritor do Processo de Trabalho, em todas as turmas, os profissionais-alunos foram divididos em grupos de, em média, seis alunos, para discutir dois casos relacionados com o percurso terapêutico de duas mulheres que buscaram atenção à saúde desde a gestação até o puerpério. Um dos casos enfatizava o sucesso de uma das mulheres ao buscar os serviços de saúde para atender às suas demandas. O outro apontava as dificuldades encontradas por uma mulher ao buscar atendimentos desde a UBS até o hospital. A ideia era de que os profissionais-alunos pudessem perceber os nós críticos do processo de trabalho dos serviços que compõem a Rede de Atenção à Saúde (RAS) e, a partir deles, pensar nas possibilidades de mudanças. Após discussão interna de cada grupo, as reflexões foram compartilhadas com todo o grupo. A partir dessa vivência, foi proposto que cada participante realizasse, na sua equipe, a análise do seu processo de trabalho utilizando da ferramenta Fluxograma Descritor do Processo de Trabalho, e que relatasse, através da construção de uma narrativa, como se deu esse processo. Essa narrativa corresponderia à atividade avaliativa 1 .

Uma dificuldade que apareceu em relação ao Fluxograma Descritor do Processo de trabalho foi o fato de ter dado margem para alguns profissionais-alunos, especialmente os enfermeiros, pensarem na ferramenta como uma forma de prescrever fluxos e determinar regras, em detrimento da construção coletiva da análise sobre seu próprio processo de trabalho. Isso sugere um certo engessamento que a palavra 'fluxograma' pode representar, já que pode ser entendida como algo estático, em que alguém deve ditar como o trabalho deve ser feito. Essa percepção possibilitou que fossem pensadas estratégias, para as turmas seguintes, que deslocassem o foco da palavra 'fluxograma', para analisar o itinerário percorrido pelo usuário dentro do serviço. Assim, foi possível analisar o fluxo dos serviços a partir do caminho percorrido pelo usuário, identificando os nós críticos que foram aparecendo nesse processo.

Ainda no primeiro encontro, no sentido de identificar nós críticos do processo de trabalho e fazê-lo de forma coletiva para também construir alternativas compartilhadas para os problemas identificados, foram ofertadas outras ferramentas, como os Processos Circulares. Esses são considerados como importantes ferramentas para ampliação do diálogo na construção do trabalho em equipe ${ }^{15}$ e podem ser realizados para debater diversos temas, como, por exemplo, identificação de problemas na equipe, alcance de metas, avaliação do trabalho, entre outras. Essa ferramenta foi utilizada em todas as UA, sendo considerada por todos os envolvidos como aquela que mais propiciou transformações nos espaços de trabalho.

Quando se realiza um Processo Circular, é necessário que todos estejam em círculo e que haja um objeto, no centro da roda, simbolicamente importante para o grupo ${ }^{15}$. É necessário também pactuar um tempo de fala por pessoa, sendo que ele é controlado por alguém do grupo. Quando está com a palavra, a pessoa deve segurar um outro objeto chamado de 'bastão da fala', um objeto que também, preferencialmente, faça algum sentido para o grupo. O 'bastão da fala' deve passar por todos e, apenas quem o está segurando possui direito a fala. Enquanto uma pessoa encontra-se com o 'bastão da fala', as demais devem ouvir e respeitar o momento daquela que o possui, mesmo que não concordem ou que tenham contribuições a fazer. Somente estarão autorizadas a falar quando estiverem segurando o bastão. Essa ferramenta foi apelidada carinhosamente como o 'bastão da fala'. Segundo 
os profissionais-alunos, essa ferramenta tem sido utilizada nos seus ambientes de trabalho, como nas reuniões de equipe, permitindo que todos possam se expressar, permitindo um maior compartilhamento nas decisões.

Em relação ao segundo encontro presencial, que acontece no meio do curso, este tem uma importância fundamental, pois é quando o grupo se reencontra após ter construído uma relação virtual pelo AVA, a partir das trocas de experiências, sentimentos, percepções, de apoio às dificuldades e às frustrações. Também é um espaço no qual é proposto resgatar o que foi produzido na UAl, trabalhar a ferramenta de gestão de materiais propostas para a UA2, e ainda introduzir a UA3, já que o último encontro acontece apenas ao final do curso, momento em que as narrativas finais são apresentadas.

Algo que se destacou, nesse segundo encontro presencial nas três turmas, foi a discussão do Projeto Terapêutico Singular (PTS). Essa ferramenta envolve a organização de um conjunto de condutas terapêuticas discutida por uma equipe interdisciplinar com participação do público-alvo dessas condutas ${ }^{19}$. Para trabalhar com o PTS, é imprescindível que haja uma abertura da equipe visando à compreensão da necessidade de organizar o cuidado de forma articulada e participativa ${ }^{15}$. Para iniciar essa discussão, o grupo assistiu a um vídeo que representa a atuação de uma equipe de Saúde da Família diante de um problema de saúde de um usuário do serviço. No vídeo, percebeu-se como a equipe aborda e problematiza o caso com o usuário do serviço e com sua família de forma a lidar melhor com seu problema de saúde. Além do vídeo, os profissionais-alunos leram um texto, que apresentava a narrativa da abordagem de uma família pela equipe de saúde, a partir do qual puderam discutir e problematizar algumas questões, quais sejam: como o usuário pode ser um agente ativo na produção do cuidado e de sua própria saúde? Quais os meios de ampliar a escuta feita pela equipe? Como fazer com que a complexidade da vida do usuário permita aos trabalhadores uma compreensão dos sofrimentos para além do processo saúde-doença?

Esses questionamentos produziram um debate caloroso em torno de diferentes entendimentos relacionados com as estratégias de cuidado prestadas pelas equipes de saúde. A partir da discussão, foi proposta como atividade de dispersão a construção de um PTS nas respectivas equipes de trabalho, com a coparticipação dos sujeitos envolvidos nas decisões relacionadas com o seu processo saúde-doença-cuidado. As reflexões sobre essa atividade se materializaram em uma narrativa, que representa uma das atividades avaliativas do curso. Praticamente em todas as narrativas sobre o PTS foram abordados casos que já eram caracterizados como complexos pelas equipes e que geravam uma sensação de impotência e frustração, especialmente por, geralmente, tratar-se de pessoas que se negavam a 'cumprir' as prescrições feitas pela equipe. A partir da construção do PTS, outras formas de produção de cuidado começaram a ser pensadas, especialmente iniciando um processo de trazer o usuário para o centro da atenção à saúde, de forma a considerar seus desejos, planos de felicidade e motivações, compreendendo que os desejos aglutinam uma enorme quantidade de energia vital e podem ser extremamente terapêuticos ${ }^{19}$. O envolvimento do usuário nas decisões sobre sua própria saúde e projeto de vida é algo que se tornou um aprendizado importante para todos.

O terceiro encontro presencial acontece ao final do curso e é um momento destinado ao compartilhamento das narrativas produzidas pelos profissionais-alunos entre si. As narrativas são instrumentos que possibilitam aos alunos relatarem algumas experiências vividas, de forma a permitir a construção de uma postura crítico-reflexiva, já que os aspectos teóricos, geralmente, são confrontados com a realidade vivenciada. Trata-se também de um momento, em que os alunos conseguem refletir sobre suas atividades diárias, sobre conceitos aprendidos, por isso, as narrativas possuem um potencial de transformação da prática ${ }^{20-22}$. 
Apesar das narrativas serem realizadas como atividade transversal ao longo de todo o curso, como atividade final, ela tem a função de apontar como as ferramentas aprendidas e utilizadas fizeram sentido no ambiente de trabalho. Foi possível observar que, no início do curso, a maior parte das narrativas apresentava um enfoque descritivo e resumido sobre como os encontros presenciais e virtuais tinham ocorrido. Foi necessário estímulo constante da tutora para que os profissionais-alunos pudessem escrever e refletir sobre a experiência vivenciada. Para eles, tratou-se de um exercício complexo, sendo que muitos relataram dificuldades em expressar seus questionamentos ante a realidade vivenciada no curso e nos respectivos serviços de saúde, articulando-a aos referenciais teóricos. Percebemos, a partir da construção da narrativa final, que o processo de escrita foi algo desafiador para os profissionais-alunos, mas com potencial importante para permitir uma reflexão da prática cotidiana.

Isso pôde ser evidenciado quando da apresentação das narrativas finais, que se mostrou um momento muito especial para todos os grupos. Como critério de apresentação, os profissionais-alunos deveriam ser criativos para mostrarem as suas afecções aos demais participantes. Dessa forma, utilizaram o conteúdo das narrativas para produzir músicas, teatros, vídeos e cartazes que refletiam o aprendizado de cada um, destacando as transformações que ocorreram nos respectivos serviços de saúde ao longo dos seis meses de curso. Entre as turmas de 2016 e 2017, que já concluíram o curso, os principais assuntos escolhidos para a construção das narrativas finais foram o Fluxograma Descritor do Processo de Trabalho, os Processo Circular e o PTS, o que nos faz acreditar que essas ferramentas foram consideradas como as que mais auxiliam no desenvolvimento de competências para a prática gerencial. Todas as narrativas demonstraram ainda um envolvimento singular das equipes, indicando que elas vivenciaram o processo de forma coletiva.

\section{Considerações finais}

As experiências e as reflexões aqui relatadas a partir do processo de ensino da gerência em UBS tiveram como foco a oferta de ferramentas para o desenvolvimento do trabalho gerencial. Foi possível perceber que os temas e as ferramentas utilizadas, ao longo das três turmas formadas pelos profissionais que atuam no estado de Minas Gerais, permitiram reflexões sobre o processo de trabalho em todos os envolvidos. As ferramentas parecem ter sido pertinentes à realidade dos profissionais-alunos que, por meio das narrativas, demonstraram a apropriação delas, a partir do sentido que deram ao conhecimento produzido, levando-as aos diversos espaços nos quais atuam.

Foi possível perceber, porém, que essa apropriação não se deu de forma simples e natural, já que exigiu de todos um esforço de repensar como vivenciam o próprio trabalho na UBS. Dessa maneira, eles vivenciaram conflitos diversos tanto nos encontros virtuais e presenciais, quanto nos próprios ambientes de trabalho. Isso demonstra a potência das ferramentas para a reflexão de nossas posições e do processo de trabalho em equipe, já que nos permite construir novos olhares sobre os nossos ambientes de trabalho. Assim, o desenvolvimento e o uso de ferramentas gerenciais nesse curso parecem ser fundamentais para a qualificação da gerência de UBS.

\section{Colaboradores}

Pertile KC (0000-0002-0286-3171)* e Hemmi APA (0000-0003-3513-9523)* contribuíram substancialmente para a concepção, planejamento, análise, interpretação dos dados, escrita e revisão final do manuscrito. Miranda $\mathrm{CZ}$ (0000-0003-1889-5845)* e Santos FF (00000003-3823-2416)* contribuíram significativamente para a elaboração do rascunho e revisão crítica do conteúdo. 


\section{Referências}

1. Campos GWS. Considerações sobre a arte e a ciência da mudança: revolução das coisas e reforma das pessoas, o caso da saúde. In: Cecílio LCO, organizador. Inventando a mudança na saúde. 3. ed. São Paulo: Hucitec; 2006. p. 29-87.

2. Merhy EE. $\mathrm{O}$ ato de governar as tensões constitutivas do agir em saúde como desafio permanente de algumas estratégias gerenciais. Ciênc. Saúde Colet. [internet]. 1999 [acesso 2019 fev 14]; 4(2):305-314. Disponível em: http://www.scielo.br/scielo.php?script=sci arttext\&pid=S1413-81231999000200006\&lng=en\& nrm=iso.

3. Brasil. Ministério da Saúde. Secretaria de Atenção à Saúde. Departamento de Atenção Básica. Política Nacional de Atenção Básica. Brasília, DF: Ministério da Saúde; 2012.

4. Brasil. Ministério da Saúde. Portaria no 2.436, de 21 de setembro de 2017. Aprova a Política Nacional de Atenção Básica, estabelecendo a revisão de diretrizes para a organização da Atenção Básica, no âmbito do Sistema Único de Saúde (SUS). Diário oficial da União. 22 Set 2017.

5. Nunes LO, Castanheira ERL, Dias A, et al. Importância do gerenciamento local para uma atenção primária à saúde nos moldes de Alma-Ata. Rev Panam Salud Publica. 2018; 42:e175.

6. Deus AD, Melo EM. Avaliação de uma experiência de gestão hospitalar participativa no âmbito do SUS: produção de saúde, sujeitos e coletivos. Saúde debate. Rio de Janeiro. 2015; 39(106):601-615.

7. Cunha MLS, Hortale VA. Características dos cursos voltados para a formação em gestão em saúde no Brasil. Saúde debate [internet]. 2017 [acesso $2018 \mathrm{dez} 13$ ]; 41(113):425-440. Disponível em: https://www.scielosp.org/article/sdeb/2017.v41n113/425-440/pt/.

8. Educação Permanente em Saúde em Movimento [internet]. Refletindo sobre ferramentas analisadoras [acesso 2019 jan 5]. Disponível em: http://eps.otics. org/material/entrada-textos/refletindo-sobre-ferramentas-analisadoras.

9. Merhy EE. Saúde: a cartografia do trabalho vivo. São Paulo: Hucitec; 2002.

10. Berbel NAN. Metodologia da Problematização no Ensino Superior e sua contribuição para o plano da praxis. Londrina: Semina; 1996.

11. Ribeiro VMB, Ciuffo RS. Sistema Único de Saúde e a Formação dos Médicos: um diálogo possível? Interface comun saúde educ. 2008; 12(24):125-140.

12. Scherer S, Brito GDS. Educação a distância: possibilidades e desafios para a aprendizagem cooperativa em ambientes virtuais de aprendizagem. Educ rev [internet]. 2014 [acesso 2019 maio 18]; (esp4):53-77. Disponível em: http://www.scielo.br/scielo.php?script=sci arttext\&pid=S0104-40602014000800053\&lng=en\& nrm=iso.

13. Maciel IM. Educação a distância. Ambiente virtual: construindo significados. Boletim Técnico do SENAC. 2018; 28(3):38-45.

14. Ohira RHF, Cordoni Junior L, Nunes EFPA. Perfil dos gerentes de Atenção Primária à Saúde de municípios de pequeno porte do norte do Paraná, Brasil. Ciênc. Saúde Colet. 2014; 19(2):393-400

15. Abraão AL, Cardoso A, Cordeiro B, et al. Curso de Aperfeiçoamento em Gerência de Unidades Básicas de Saúde, Gestão da Clínica e do Cuidado. Niterói: CEAD-UFF; 2016.

16. Merhy EE. Engravidando as palavras: o caso da integralidade. In: Pinheiro R, Mattos R, organizadores. Construção social da demanda. Rio de Janeiro: IMS-UERJ, Abrasco; 2005. p. 195-206.

17. Alberti TF, Abegg I, Costa MRJ, et al. Dinâmicas de grupo orientadas pelas atividades de estudo: desenvolvimento de habilidades e competências na educação profissional. Rev Bras Estud Pedagog [in- 
ternet]. Brasília, DF. 2014 [acesso 2019 maio 18]; 95(240):346-362. Disponível em: http://www.scielo.br/scielo.php?script=sci_arttext $\&$ pid $=$ S2176$-66812014000200006 \& \operatorname{lng}=$ en\&nrm=iso.

18. Franco TB, Merhy EE. Programa Saúde da Família (PSF): Contradições de um Programa Destinado à Mudança do Modelo Tecnoassistencial. In: Merhy EE. O Trabalho em Saúde: olhando e experienciando o SUS no cotidiano. São Paulo: Hucitec; 2003. p. 55-124.

19. Brasil. Ministério da Saúde. Secretaria de Atenção à Saúde. Núcleo Técnico da Política Nacional de Humanização. Clínica ampliada, equipe de referência e projeto terapêutico singular. 2. ed. Brasília, DF: Ministério da Saúde; 2007. Série B. Textos Básicos de Saúde.
20. Ordaz O. O uso das narrativas como fonte de conhecimento em enfermagem. Pensar enfermagem. 2011; 15(1):70-87.

21. Fortuna CM, Gonçalves MFC, Silva MAI, et al. A produção de narrativas crítico-reflexivas nos portfólios de estudantes de enfermagem. Rev Escola Enferm. USP. 2012; 46(2):452-459.

22. Oliveira RMA. Narrativas: contribuições para a formação de professores, para as práticas pedagógicas e para a pesquisa em educação. Rev Educ Pública. 2012; 20(43):289-305.

Recebido em 17/02/2019

Aprovado em 23/09/2019

Conflito de interesses: inexistente

Suporte financeiro: não houve 